\title{
Andreas Bähr, Der grausame Komet. Himmelszeichen und Weltgeschehen im Dreißigjährigen Krieg
}

\section{Claire Gantet}

\section{OpenEdition}

\section{Journals}

Édition électronique

URL : http://journals.openedition.org/ifha/10084

DOl : $10.4000 /$ ifha. 10084

ISSN : 2198-8943

\section{Éditeur}

IFRA - Institut franco-allemand (sciences historiques et sociales)

\section{Référence électronique}

Claire Gantet, «Andreas Bähr, Der grausame Komet. Himmelszeichen und Weltgeschehen im Dreißigjährigen Krieg », Revue de l'IFHA [En ligne], Date de recension, mis en ligne le 18 avril 2019, consulté le 24 septembre 2020. URL : http://journals.openedition.org/ifha/10084 ; DOI : https:// doi.org/10.4000/ifha.10084

Ce document a été généré automatiquement le 24 septembre 2020.

(C)IFHA 


\section{Andreas Bähr, Der grausame Komet. Himmelszeichen und Weltgeschehen im Dreißigjährigen Krieg}

Claire Gantet

\section{RÉFÉRENCE}

Andreas Bähr, Der grausame Komet. Himmelszeichen und Weltgeschehen im Dreißigjährigen Krieg, Reinbek bei Hamburg : Rowohlt, 2017, 303 p., 19,95€ 
La conjoncture des 400 ans du début de la guerre de Trente ans, en 1618, a donné lieu à une intense activité éditoriale en 2017 et 2018. Des synthèses « commerciales ", l'ouvrage d'Andreas Bähr se distingue par son information fortement appuyée sur des sources primaires et son refus de se livrer à un récit englobant. Il mérite donc le respect. Dans cet ouvrage accessible à un vaste public, il propose de sonder les « interprétations » par les contemporains de la violence de la guerre telles qu'elles sont exprimées dans cinq chroniques qui ont déjà fait l'objet d'une édition critique (sur papier ou en ligne) et sont parfois bien connues des historiens. Andreas Bähr prend garde de croiser des documents protestants - le Zeyregister du cordonnier luthérien Hans Heberle d'Ulm, le Kleines Biechlin du fondeur d'étain et pâtissier-

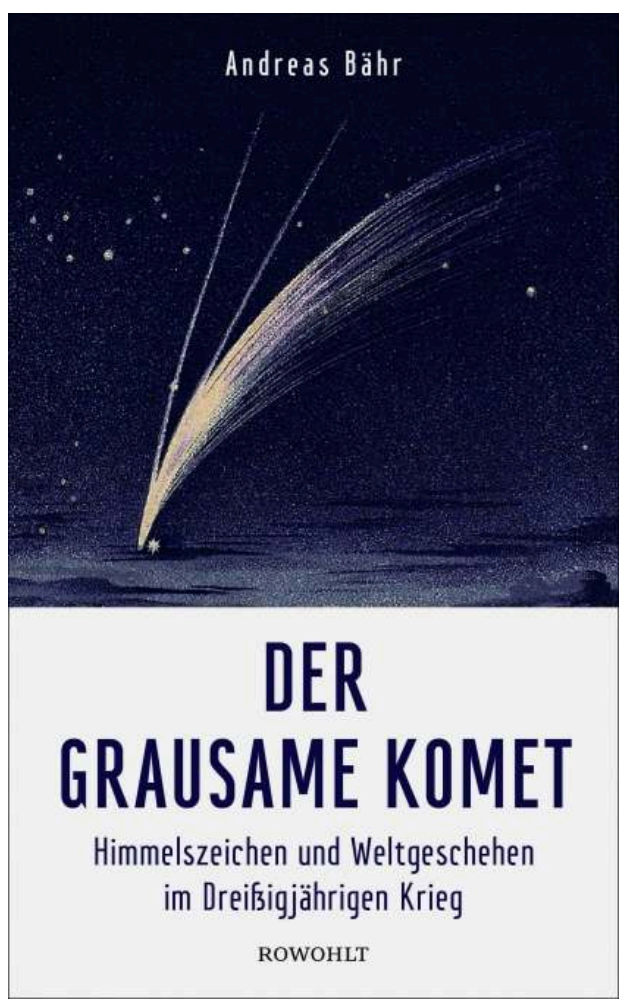
confiseur alsacien réformé Augustin

Güntzer, le Chronicon Thuringiae du directeur de chancellerie luthérien Volkmar Happe - et catholiques - les Collectanea du cistercien Sebastian Bürster du lac de Constance, la Vita du savant jésuite Athanasius Kircher - sans au reste relever entre eux de différence fondamentale dans l'écriture de la providence. L'objet central du livre, la comète de novembre-décembre 1618 (connue de nos jours sous le nom C/1618 WI) a déjà fait l'objet de la thèse très approfondie de Marion Gindhart; les études sur les "égo-documents", la providence et la cosmologie (que l'on pense au mémoire d'habilitation de Kaspar von Greyerz sur les diaires anglais du XVII ${ }^{\mathrm{e}}$ siècle) ainsi que sur les prodiges sont légions. Le but d'Andreas Bähr n'est pas de réécrire ce qui l'a déjà fort bien été, mais de proposer un récit de la guerre qui plonge le lecteur dans les cadres de pensée du début du XVII ${ }^{\mathrm{e}}$ siècle. Ce livre ne relève donc pas de l'anthropologie historique en ce qu'il ne traite pas de rites ou de gestes, mais plutôt d'une histoire des mentalités.

Il traite des interprétations du passage de la comète perçue en novembredécembre 1618 comme signifiant le début de la guerre, dès 1618 et encore plus rétrospectivement en 1648 : c'est ainsi que les conflagrations commencèrent à être unifiées en une "guerre de Trente ans ». L'écriture d'A. Bähr hésite entre la volonté littéraire de restituer un climat et l'analyse historique. Après un premier chapitre d'introduction, le chapitre deux sur les «controverses » se situe nettement au niveau de l'analyse, puisqu'il contextualise le traité latin de Johannes Kepler paru en 1619. Les chapitres suivants, eux, très proches des chroniques, se situent plutôt au niveau de la reconstitution de perceptions générales ou d'un «vécu ». A. Bähr inscrit la comète dans l'ensemble des "prodiges» et passe aux rêves présentés comme prémonitoires du mélancolique Augustin Güntzer (chapitre quatre), à la prédiction du sac de Magdebourg à la vue d'aurores boréales en 1630 ainsi qu'à l'Élégie de Petrus Lotichius (chapitre cinq), et aux visions nocturnes d'Athanasius Kircher à Wurtzbourg (chapitre six). Le terme de 
"prodiges » est très vaste, et l'on s'étonne qu'A. Bähr n'ait pas songé à situer ses sources par rapport aux feuilles volantes et almanachs contemporains, et qu'il n'ait pas traité de l'instrumentalisation politique des "prodiges " ou de la frontière instable entre prodige et miracle. Le choix de se concentrer sur cinq sources et sur quelques récits de rêves semble finalement découler de la fascination personnelle de l'auteur pour ces textes. Le dernier chapitre relève le passage d'une comète en septembreoctobre 1914 et des réactions religieuses : le souvenir de la comète de 1618 semble ne s'être pas tari.

Le livre hésite donc entre deux modes narratifs et, à l'instar de l'histoire des mentalités, est dépourvu d'approche critique des sources mobilisées. Les historiens resteront vraisemblablement sur leur faim. Il est toutefois très bien informé (à l'exception du travail d'Anthony Grafton sur les visions d'Athanasius Kircher, étonnamment inconnu). Surtout, ce qui l'emporte, c'est la fascination pour une époque clé. Pour un public plus vaste, ce livre est une mine de renseignements très bien écrite et en peu de mots, où pointe parfois aussi un certain humour - ainsi p. 63 sur le Danube comme fleuve savant, ou p. 73 sur le «sommeil durant le sermon"-, et un accès excellent à des interrogations du XVII ${ }^{e}$ siècle et des sources primaires.

INDEX

Thèmes : Histoire des mentalités

Index chronologique : Période moderne

\section{AUTEURS}

CLAIRE GANTET

Université de Fribourg (Suisse)/Universität Freiburg (Schweiz) 